\subsection{4 doi: 10.15789/2220-7619-2018-4-7.14 \\ PARENTERAL VIRAL HEPATITIS IN CHILDREN IN RUSSIA, PARTICULARLY IN THE NORTHWESTERN FEDERAL DISTRICT}

A.A. Sukhoruk ${ }^{1,2}$, E.V. Esaulenko ${ }^{1,2}$, N.V. Ivanova ${ }^{1}$

${ }^{1}$ St. Petersburg Pasteur Institute, St. Petersburg, Russia, ${ }^{2}$ St. Petersburg

State Pediatric Medical University, St. Petersburg, Russia

Among acute viral hepatitis in children aged 0 to 14 years nosological entities with enteric transmission prevail over the parenteral ones which account for not more than $3-5 \%$. Thus, in 2017 out of 1851 cases of acute viral hepatitis reported in the Russian Federation among the children under 15 years of age 10 cases were of acute hepatitis B and 40 cases - of acute hepatitis C. 417 Cases of chronic viral hepatitis in children aged $0-14$ years were reported in Russia in 2017. As well as in adult population, chronic hepatitis C predominates, accounting for $83.7 \%$ of all reported cases. Relative share of chronic hepatitis B is $14.9 \%$ and that of an unspecified chronic hepatitis - $1.4 \%$. Preventive measures against infection with hepatitis B and hepatitis $\mathrm{C}$ contributed to significant decrease in the parenteral hepatitis incidence rate. Timely implementation of a wide hepatitis B immunization program for 1-year old children in the Northwestern federal district resulted in the fact that since 2013 the number of cases of acute hepatitis B has not exceeded 1-2 and in some years, there were no such cases at all. Within the Northwestern federal district in 2009-2010 acute hepatitis C was reported both in infants and older children. Decrease in incidence rate in infants from 5.1 per 100000 people in 2009 down to 1.78 per 100000 people in 2017, as well as lack of reported cases in older age groups, shows the improvement of epidemiological situation. The incidence rate of chronic hepatitis $\mathrm{B}$ and hepatitis $\mathrm{C}$ in children is more than 40 times lower than the incidence rate in adults. In 2017 in the Northwestern federal district the incidence rate of chronic hepatitis $\mathrm{C}$ in children was 6.5 times higher than that of chronic hepatitis B (1.5 and 0.2 per 100000 people, respectively). Despite of positive dynamics in the parenteral hepatitis incidence rate, the total number of pediatric patients in the Northwestern federal district over the last years has remained constant (250-300 children), and the attack rate in 2017 was 3.7 per 100000 people in case of chronic hepatitis B and 11.7 per 100000 people in case of chronic hepatitis $\mathrm{C}$. Thus, in spite of decrease in its incidence rate in children, the problem of post-transfusion hepatitis infection remains of high concern.

\subsection{5}

doi: 10.15789/2220-7619-2018-4-7.15

\section{MONITORING OF LONG-TERM ANTIVIRAL TREATMENT OF CHRONIC HEPATITIS B}

\section{A.A. Sukhoruk ${ }^{1,2}$, K.A. Zakharov ${ }^{2}$}

${ }^{1}$ St. Petersburg Pasteur Institute, St. Petersburg, Russia; ${ }^{2}$ St. Petersburg State Pediatric Medical University, St. Petersburg, Russia

Rapidly progressing and hard to treat $\mathrm{HBeAg}$-negative chronic hepatitis B is for the prevalent type of the disease in the world, including Russia. Antiviral therapy by nucleo$\mathrm{t}(\mathrm{z})$ ide analogues is aimed at the permanent suppression of hepatitis B virus replication. Undefined duration of the nucleot(z)ide analogues treatment in $\mathrm{HBeAg-negative}$ patients is a serious problem taking into account absence of adequate predictors of the disease course after treatment discontinuation. Thus, our task is to analyze the results of the long-term antiviral therapy of $\mathrm{HBeAg}$-negative chronic hepatitis B patients. Analysis was performed in 79 $\mathrm{HBeAg}$-negative patients with confirmed chronic hepati- tis B who had not previously treated. The administration medicine was telbivudine in a daily dose of $600 \mathrm{mg}(\mathrm{n}=49)$ or entecavir in a daily dose of $0.5 \mathrm{mg}(\mathrm{n}=30)$. The therapy course, which lasted from 5 months to 7 years, also included patients with a viral load less than $2.0 \times 10^{4} \mathrm{IU} / \mathrm{ml}$ in presence of severe hepatic fibrosis (F3 or F4 stages by METAVIR). Efficacy of the treatment was evaluated based on the activity of ALT and the level of HBV DNA, monitoring also included the biochemical and serological parameter measurements. The study had shown that viral load reached undetectable levels in $92.3 \%$ of cases after 52 weeks of therapy $(\mathrm{p}<0.05)$. Five patients out of six non-responders, received telbivudine. A significant decrease in the proportion of patients with ALT levels above upper line normal (16.8\% vs. $44.3 \%$ at the beginning of the treatment), as well as severity of cytolytic activity (ALT levels $109.8 \pm 102.4 \mathrm{IU} / \mathrm{L}$ vs. $68.8 \pm 39.2 \mathrm{IU} / 1$ at the beginning of the treatment) $(\mathrm{p}<$ $0.05)$ were noted. The remarkable fact was the decrease in the proportion of patients responding to treatment at 104-156 weeks of antiviral therapy. In most cases, failure of the therapy was associated with the telbivudine administration, and telbivudine replacement with entecavir was associated with increase of the virological response rates. Thus, it can be concluded that treatment with telbivudine is currently impractical due to the high level of virological breakthroughs. Entecavir has demonstrated higher efficacy during the treatment, lasting for up five or more years. However, there is a number of issues related to the prediction of the relapse risks after discontinuation of the nucleot(z)ide analogues therapy, which remains unsolved and requires further studying.

\subsection{6} doi: 10.15789/2220-7619-2018-4-7.16

\section{DEVELOPMENT AND APPROBATION METHOD OF IDENTIFICATION MUTATIONS THE RESISTANCE OF THE HEPATITIS C VIRUS TO DIRECT-ACTING ANTIVIRAL AGENTS (DAAs)}

\section{D.E. Valutite, Yu.V. Ostankova}

\section{St. Petersburg Pasteur Institute, St. Petersburg, Russia}

Hepatitis C Virus (HCV) treatment has been improved dramatically thanks to the introduction of direct-acting antiviral agents (DAAs). These antivirals have significantly increased response rates (up to 98\%) and greatly reduced treatment duration. Currently available DAAs are classified into four categories given their molecular targets in the $\mathrm{HCV}$ replication cycle: NS3/4A protease inhibitors bind to the active site of the NS3/4A protease; NS5A inhibitors interact with domain 1 of the NS5A dimer; nucleotide analog NS5B polymerase inhibitors are incorporated into the nascent RNA chain resulting in chain termination by compromising the binding of the incoming nucleotide; nonnucleoside NS5B polymerase inhibitors. However, the high replication rates of $\mathrm{HCV}$, can lead to the extreme mutations in the virus.

The objectives were development and approbation the method of identification mutations the resistance of the hepatitis $\mathrm{C}$ virus to direct-acting antiviral agents (DAAs).

The subtype-specific oligonucleotides were designed based on HCV sequence alignments from NCBI HCV database. The sequences were retrieved with the inclusion criteria of belonging to full genome sequences (confirmed non-recombinant genomes), being devoid of large insertions/deletions, and corresponding to $1 \mathrm{a}, 1 \mathrm{~b}, 2 \mathrm{a}$. It is these subtypes that are most common in Russia. Specific oligonucleotides were designed to therapeutically relevant regions: NS3/4A, NS5A, NS5B. 